\title{
Optimizing palm biomass energy though size reduction
}

\begin{abstract}
Solids oil palm biomass in the form of empty fruit bunches (EFB), palm press fibre (PPF), palm kernel shell (PKS), palm trunks and fronds has been identified as one of the main source of renewable energy with great potential in Malaysia. Recent development in the industry requires proper treatment of the palm biomass so that it generates clean energy. One of the treatment of palm biomass is size reduction since this will remove excess moisture and oil. It is vital to establish the correlations between size of palm biomass on moisture and the calorific values. By modeling and simulation, optimised blends of palm biomass consisting of EFB, PPF and PKS can be mixed to give the maximum power output. The physical and calorific properties of palm biomass were established through experimental work as well as plant data collected in this study. The simulated palm biomass blends through this study was validated with plant data from previous studies. Size reduction reduced moisture content significantly in the oil palm biomass namely EFB from 52 to $40 \%$. With size reduction, the calorific values of blends can increase by $34 \%$ and further improve the Net Energy Availability Value. The study suggests that an optimised blend from the oil palm biomass would further improve the calorific value. Through improved processing technology, the palm oil industry will continue to strive for sustainability development addressing both social and economic aspect simultaneously.
\end{abstract}

Keyword: Biomass blends; Moisture; Palm biomass; Renewable energy; Size reduction 